\title{
THE NATURE OF A HEAT WAVE IN EASTERN ARGENTINA OCCURRING DURING SALLJEX
}

\author{
S. Bibiana Cerne *, Carolina S. Vera \\ Centro de Investigaciones del Mar y la Atmósfera (CIMA) - CONICET \\ Departamento de Ciencias de la Atmósfera y los Océanos - \\ Universidad de Buenos Aires - Argentina \\ and \\ Brant Liebmann \\ NOAA-CIRES/Climate Diagnostics Center \\ Boulder, Colorado
}

\begin{abstract}
This paper describes the physical processes associated with the occurrence of a heat wave over central Argentina during the austral summer of 2002-2003, during which the South American Low-Level Jet Experiment (SALLJEX) was carried out. The SALLJEX heat wave that lasted between 25 January and 2 February of 2003 was punctuated by extreme conditions during the last 3 days with the largest historical temperature recorded over the last 35 years in several stations of the region. It was found that not only the activity of synoptic scale waves, but also the intraseasonal oscillation variability had a strong impact on the temperature evolution during that particular summer. During the weeks previous to the heat wave development, an intensified South Atlantic Convergence Zone (SACZ) dominated the atmospheric conditions over tropical South America. Temperature started to increase in the subtropics due to the subsidence and diabatic warming associated with the SACZ, as depicted by SALLJEX upper-air observations. An extratropical anticyclone that evolved along southern South America further intensified subsidence conditions. By the end of January the warming processes associated with SACZ activity weakened, while horizontal temperature advection begun to dominate over central Argentina due to the intensification of the South American Low-Level Jet. The approach of an extratropical frontal system produced the maximization of such mechanisms leading to temperature extremes by 2 February with temperature anomalies at least two standard
\end{abstract}

\footnotetext{
" Corresponding author address: Bibiana Cerne, Centro de Investigaciones del Mar y la Atmósfera (CONICET) and Departamento de Ciencias de la Atmósfera y los Océanos (UBA), cerne@cima.fcen.uba.ar
}

deviations larger than the climatological mean values.

\section{Introduction}

The analysis and prediction of temperature and its persistence are very important as extremes effects can be beneficial or harmful to a wide range of human activities. It has been documented that intense heat waves over subtropical South America produce dangerous levels of thermal stress in people (Campetella and Rusticucci 1998; Alessandro and de Garin 2003). Nevertheless, the nature and mechanisms associated with the occurrence of heat waves over this particular region have yet to be studied in detail.

Heat waves over subtropical South America have usually been associated with the activity of synoptic scale waves. Rusticucci and Vargas (1995) and Alessandro and de Garín (2003) analyzed the synoptic situations associated with intense heat waves over subtropical South America and found that northerly winds occur during most of the cases, associated with the development of a trough over central Argentina. Frontal systems approaching the region from the south also contribute to an intensification of the northerly winds favorable for the occurrence of heat waves at the subtropics (Rusticucci and Vargas 1995).

Also, there is some evidence that positive temperature anomalies may persist for periods longer than synoptic time scales over central and northern Argentina (Rusticucci 1995). Campetella and Rusticucci (1998) described the occurrence of an intense heat wave that developed over central and northern Argentina that lasted for two weeks during March 1980. The persistence of an anticyclonic circulation over southeastern South America, in conjunction with continual low-level northwesterlies flowing into the region, accounted for the high temperatures. The mechanisms associated with persistent heat waves are not 
clear yet. Moreover, the intraseasonal variability of both temperature and temperature extremes has not received any attention yet although several papers have already addressed the relevance of the intraseasonal variability of circulation and associated precipitation over subtropical South America (Liebmann et al. 2004 and references therein).

This paper will describe the physical processes associated with the occurrence of a heat wave that lasted for 9 days between 25 January and 2 February 2003 over north and central Argentina, with historical temperatures observed in several stations. The influence of the intraseasonal variability in the occurrence of such an extreme event is also addressed. Besides the extreme characteristics of this temperature heat wave, the event was also chosen because it occurred during the 2002-2003 summer in which the South American Low-Level Jet Experiment (SALLJEX) was carried out by the WCRP/CLIVAR/VAMOS Program (Vera et al. 2005). SALLJEX provided an unprecedented group of observations to describe the structure and temporal evolution of the circulation during this particular heat wave.

\section{Data}

The datasets consist of DecemberFebruary 2002-2003 National Center for Environment Prediction (NCEP) six-hourly operational analyses (GDAS) with a $1^{\circ} \times 1^{\circ}$ grid resolution available at 17 vertical levels. Temperature fields from NCEP/NCAR reanalyses (Kalnay et al 1996) were also used for comparison with GDAS and observed data. Daily averages of the National Oceanic and Atmospheric Administration (NOAA) satellite outgoing long wave radiation (OLR) field are used as precipitation proxy. Daily maximum and minimum temperatures and surface temperature for 12 UTC at Rosario, Argentina, were supplied by Argentinean National Weather Service for the period 1968-2003. Radiosonde observations from SALLJEX are available at http://www.joss.ucar.edu/salljex/dm.

The temperature analysis was made through the study of the temporal evolution of the 12 UTC (0900 local time) temperature at Rosario city $\left(32^{\circ} 55^{\prime} \mathrm{S}, 60^{\circ} 40^{\prime} \mathrm{W}\right)$ that is located at the center of the region with largest positive temperature anomalies observed over the period of study (Fig. 4e).

\section{The SALLJEX heat wave}

The time series of surface temperature recorded at Rosario city at 12 UTC during the austral summer of 2002-2003 is depicted in Fig. $1 \mathrm{a}$, including the seasonal cycle (as described by the climatologic daily temperature averages) for reference. A persistent temperature increase characterized the period between 25 January and 2 February (hereafter referred as "the SALLJEX heat wave"), that was also observed in the time series of the maximum and minimum temperatures (not shown). Moreover, the positive temperature extreme occurred on 2 February, classifies in the $95^{\text {th }}$ percentile and it is the historical recorded value for February over the 1968-2003 period.

The analysis of the conditions associated with the SALLJEX heat wave (Figure 1) shows that since 23 January, temperature begun to increase and exceeded climatology between 25 January and 2 February. Anomalies larger than one standard deviation were observed by 30 January while those occurred after 31 January exceeded the mean value by at least two standard deviations, which confirm the anomalous nature of the SALLJEX heat wave. The dew-point temperature also increased during the SALLJEX heat wave event (not shown), although at a lower rate than the temperature itself. The difference between both temperatures was $8.2^{\circ} \mathrm{C}$ on 31 January and was the maximum difference observed over all the warm periods of this particular summer. The dry conditions associated with the SALLJEX heat wave are in fact one of the most distinctive features of this event and is further investigated in the following sections.

The impact of the SALLJEX heat wave on population comfort was assessed through the calculation of the relative strain index (RSI), defined as $\mathrm{RSI}=(10.7+0.74(\mathrm{~T}-35)) /(44-\mathrm{e})$, where $\mathrm{T}$ is the air temperature in ${ }^{\circ} \mathrm{C}$, and $\mathrm{e}$ is the water vapor pressure in $\mathrm{hPa}$ (Lee and Henschel 1966). The index represents the ratio between the necessary perspiration to regulate the body temperature and the atmospheric evaporative capacity. Upper comfort thresholds for young and old people are associated with RSI values for 0.15 and 0.10 respectively, possible cardiac-respiratory problems might be expected for RSI values larger than 0.18 , while $\mathrm{RSI}$ values greater than 0.3 represent the failure threshold (loss of physiological thermal equilibrium). The analysis of the RSI evolution during the SALLJEX heat wave showed that since 28 January, it persistently increased from 0.23 and achieving dangerous values on 2 February (0.56). RSI indexes were even worse at the time of the maximum 
temperature (not shown), enhancing the levels of discomfort associated with the SALLJEX heat wave.

The temporal evolution of the surface temperature observed at Rosario, was compared with those described by GDAS analysis and NCEP reanalysis (Fig. 2), in order to assess the ability of these datasets in reproducing the SALLJEX heat wave. Both analyzed datasets are able to describe the main features of the temperature evolution, although both failed in reproducing the right values of surface temperature during the SALLJEX heat wave, being in general smaller than observed. In agreement, Rusticucci and Kousky (2002) comparing NCEP reanalysis maximum and minimum temperatures with station data over Argentina, found that reanalysis data underestimate the intensity of the extreme warm events.

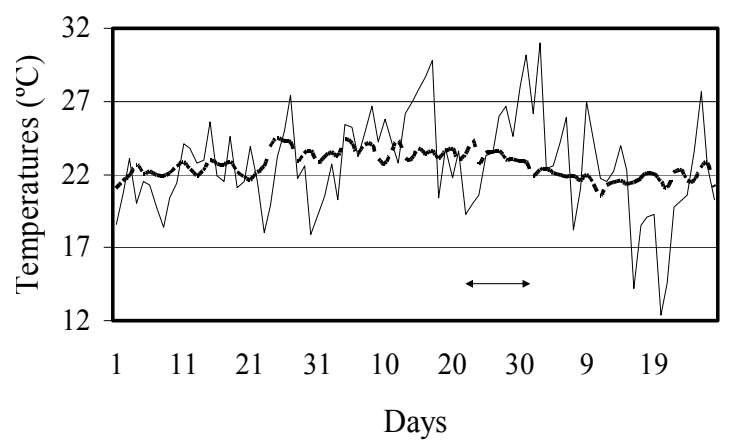

Figure 1: 12-UTC surface observations $\left({ }^{\circ} \mathrm{C}\right)$ at Rosario city (Fig. 4e) during austral summer 2002-2003: air temperature (solid) and climatological mean temperature for the (1968-2003) period.

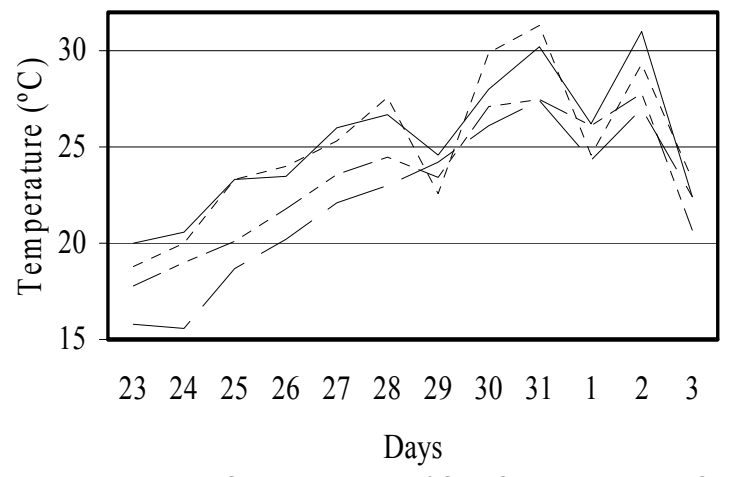

Figure 2: 12-UTC time series $\left({ }^{\circ} \mathrm{C}\right)$ of observed surface temperature (solid line), GDAS 2-m temperature (dotted line), GDAS 950-hPa temperature (dotted-dashed line), and NCEP 995-sigma temperature (long dashed line) at Rosario city between 23 January and 3 February 2003.

\section{Intraseasonal variability}

Figure 3 shows that the time series of the standardized daily temperature anomalies (departures from the mean divided by the standard deviation) at Rosario not only exhibit the typical synoptic variability, but also it exhibits a considerable intraseasonal variability (as described by the 10-90 day filtered time series of temperature anomalies). Moreover, it is particularly evident that the SALLJEX heat wave was embedded in an intraseasonal oscillation event that lasted from middle January to the beginning of February. In agreement, the spectral analysis of the temperature daily anomalies at Rosario during the austral summer of 2002-2003 (not shown) exhibited significant variability on intraseasonal timescales, particularly around 20day periods.

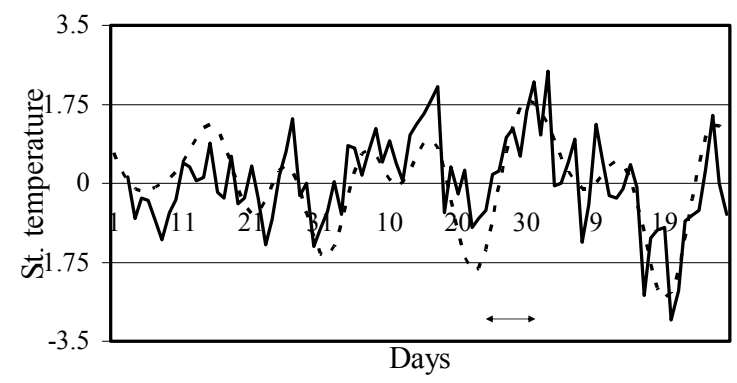

Figure 3: 12-UTC standardized surface temperature anomalies (solid line) and corresponding 10-90 day filtered anomalies (dashed line) at Rosario city during austral summer 2002-2003.

The intraseasonal evolution associated with the SALLJEX heat wave was explored through the analysis of the 5-day means of 950$\mathrm{hPa}$ temperature anomalies, OLR, wind and moisture full fields at $850 \mathrm{hPa}$ (Fig. 4). The pentad that extends from 29 January to 2 February 2003 was considered as representative of the SALLJEX heat wave and the previous pentads were defined from this particular 

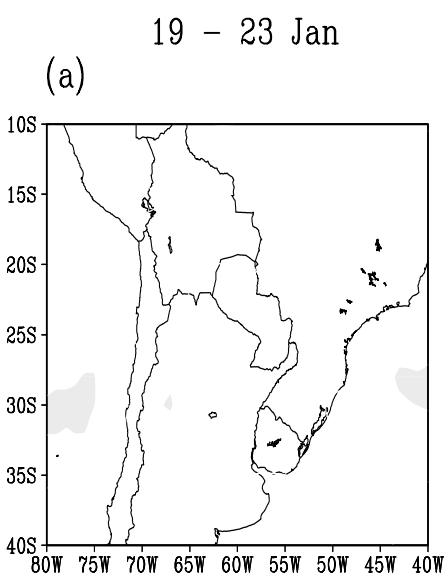

(b)

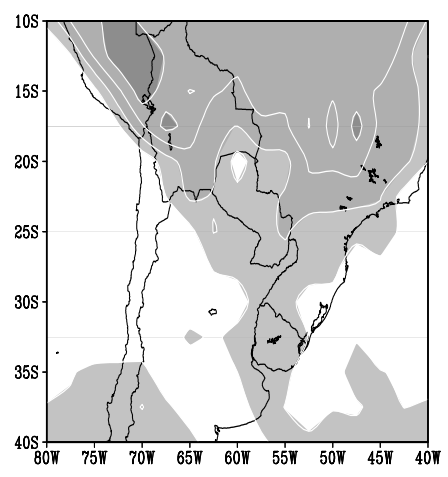

(c)

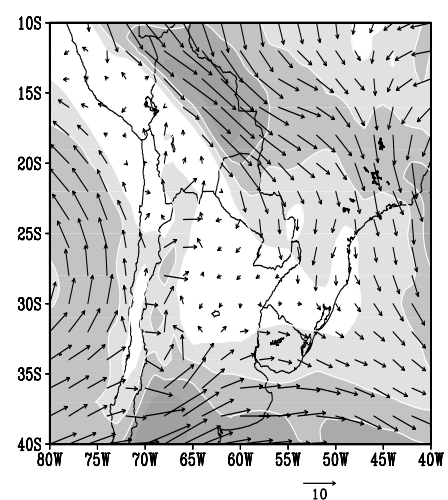

$24-28$ Jan

(d)

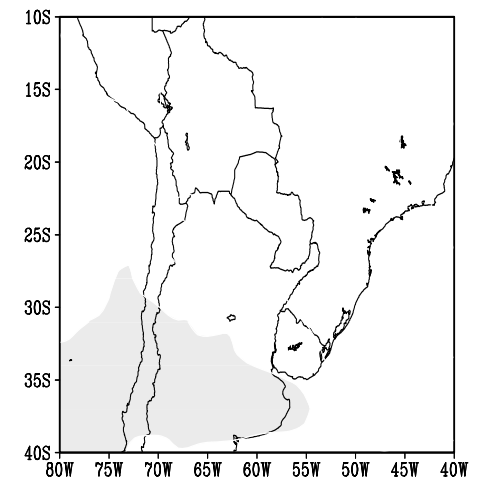

(e)

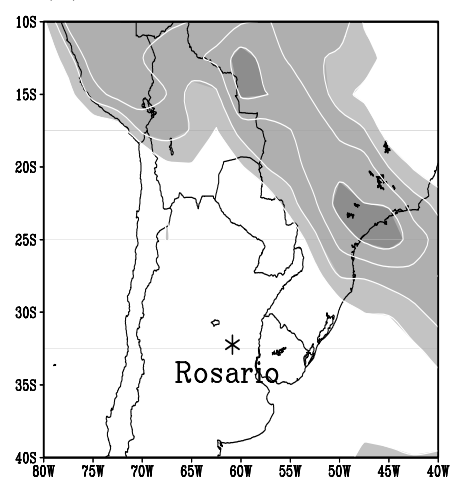

(f)

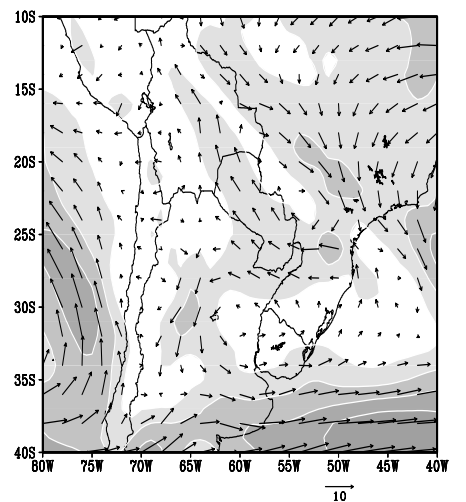

29 Jan -2 Feb

(g)

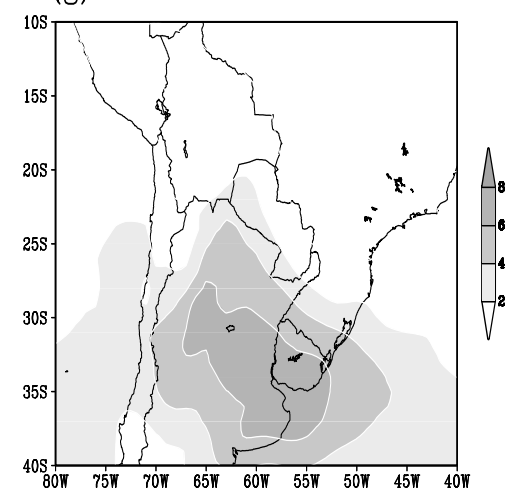

(h)

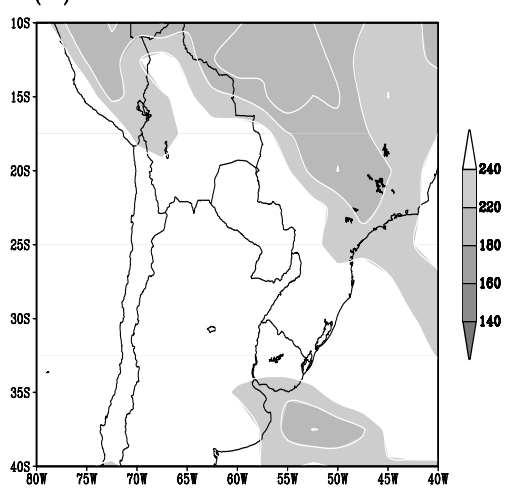

(i)

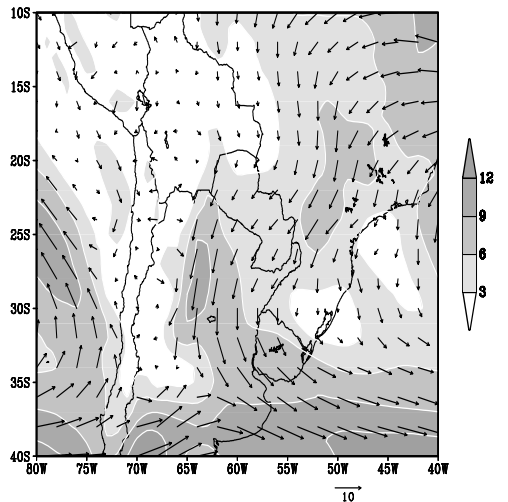

Figure 4: (Top) 925-hPa temperature anomalies, (middle) OLR, (bottom) wind vectors and specific humidity at 850 $\mathrm{hPa}$, averaged between (a, b, c) 19-23 January 2003, (d, e, f) 24-28 January 2003, and (g, h, i) 29 January-2 February 2003. Shading/contour level is $(\mathrm{a}, \mathrm{d}, \mathrm{g}) 2{ }^{\circ} \mathrm{C},(\mathrm{b}, \mathrm{e}, \mathrm{h}) 20$ watts $\mathrm{m}^{-2}$, and $(\mathrm{c}, \mathrm{f}, \mathrm{i}) 0.3 \times 10^{2} \mathrm{~g} \mathrm{~kg}^{-1}$. Wind vector reference is $10 \mathrm{~m} \mathrm{~s}^{-1}$.

Between 19 and 23 January, weak positive temperature anomalies were observed over the subtropics (Fig. 4a). The convection was intense over tropical South America (Fig. 4b) with relatively strong low-level winds over Bolivia transporting moisture eastward into southeastern
Brazil (Fig. 4c), where typically the South Atlantic Convergence Zone (SACZ) develops (e.g.

Nogues-Paegle and Mo 1997). Warming conditions increased considerably over Argentina during the next pentad (Fig. 4d) associated with drier conditions in the vicinity of Rosario city. By 
that time, the convection at the SACZ region NW low-level winds flowing into the region (Fig. 4f). Between 29 January and 2 February, large positive temperature anomalies developed over Argentina (Fig. 4g) being the largest over the whole period of study. Northerly low-level wind anomalies were quite intense towards the subtropical regions where moisture increased considerably (Fig. 4i), while the convection over the SACZ region weakened considerably (Fig. 4h).

Both the circulation and OLR features presented in Figure 4, resemble those associated with the precipitation pattern known as the South America See-Saw Pattern (SASS, Nogues-Paegle and Mo 1997). SASS has been identified as the leading pattern of precipitation variability on intraseasonal timescales, and it is characterized by a dipolar structure. Enhanced precipitation over the SACZ, decreased rainfall in the subtropical plains and a weakened SALLJ are the main characteristics of one of the SASS phases, like those displayed in Fig. 4d-f. On the other hand, the opposite phase is associated with a weakened SACZ, a southward intensification of the SALLJ, and increased rainfall at the jet exit (Fig. 4g-h). Therefore, the fact that development of warm conditions over Argentina seems to be associated first with enhanced convection in the SACZ region and drier conditions at the subtropics followed by a southward intensification of the SALLJ is certainly the most distinctive conclusion obtained from Fig. 4.

Previous works have shown that SACZ events may inhibit precipitation development over the subtropical regions due to compensatory subsidence mechanisms (Gandu and Silva Dias 1998). Cerne and Possia (2004) suggested that by the end of active SACZ periods, temperature seem to increase over Argentina. Nevertheless, the impact of the subsidence mechanism on subtropical temperature changes has not been addressed yet and thus it will be explored for the SALLJEX heat wave along the rest of the paper. The convection occurred over the SACZ region between 24 and 28 January promoted subsidence conditions (figure not shown) not only over central Argentina but also over eastern Brazil. The SALLJEX upper-air observations at Resistencia station ( $\left.27^{\circ} 27^{\prime} \mathrm{S}, 59^{\circ} 03^{\prime} \mathrm{W}\right)$ provided an excellent observational description of such subsidence conditions. On 22 January, the sounding shows moist conditions below $650 \mathrm{hPa}$ associated with weak northerlies while above, drier conditions and westerly flow are evident (not shown). Three days later, around when the SACZ (Fig. 4e) and the associated compensatory subsidence intensified (Fig. 4e); promoted by mechanisms strengthened, the sounding displays very dry and warm conditions from surface upward, and being particularly dry from $900 \mathrm{hPa}$, (Fig. 5). A greater stability, from $650-900 \mathrm{hPa}$ is also observed in the sounding compared to the previous one, presumably because of the subsidence. By 31 January, the subsidence was weakened, the lower layer was more humid and northerlies prevailed (not shown).

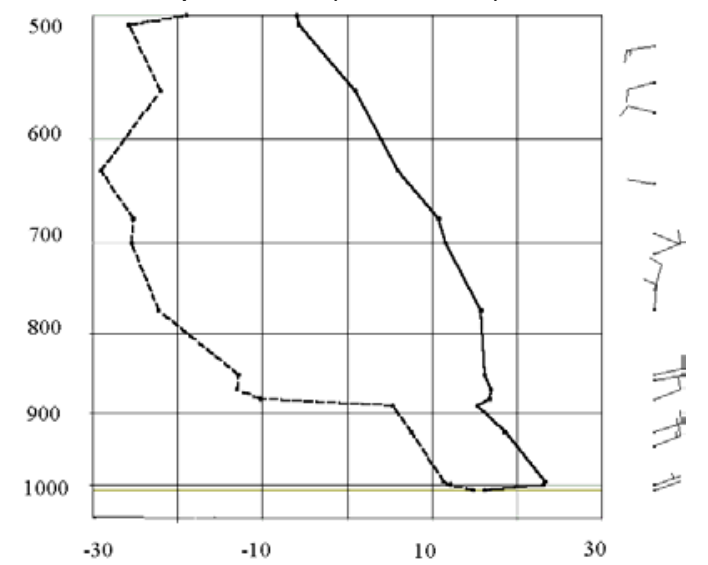

Figure 5: Vertical profiles of temperature $\left({ }^{\circ} \mathrm{C}\right)$ (solid line) and dew-point temperature $\left({ }^{\circ} \mathrm{C}\right)$ (dashed line) and wind barb (knots) at Resistencia station ( $\left.27^{\circ} 27^{\prime} \mathrm{S}, 5^{\circ} 03^{\prime} \mathrm{W}\right)$ derived from SALLJEX radiosonde observations at 25 January, 06 UTC.

\section{Synoptic wave activity}

Besides the strong modulation of the temperature variability at Rosario by the intraseasonal oscillation activity observed in this particular case, the synoptic wave activity also played a role in determining the main circulation patterns that controlled the temperature changes. Figure 6 describes the synoptic conditions in the week preceding the occurrence of the temperature extreme event on 2 February. On 27 January, the penetration from the South Pacific of an extratropical anticyclone into the continent (Fig. 6b) promoted an additional source of subsidence at the extratropical regions besides that associated with the SACZ. The Bolivian High was well developed over the eastern South Pacific but also far from its climatological position (Fig. 7a). The upper-level trough-ridge system typically associated with the SACZ was also well-built. On 29 January (not shown), the surface anticyclone moved over the southwestern Atlantic while a frontal system progressed eastward along the southern part of South America, linked with a distinctive cyclone located in the vicinity of the Antarctic Peninsula. By that time, the Bolivian High 

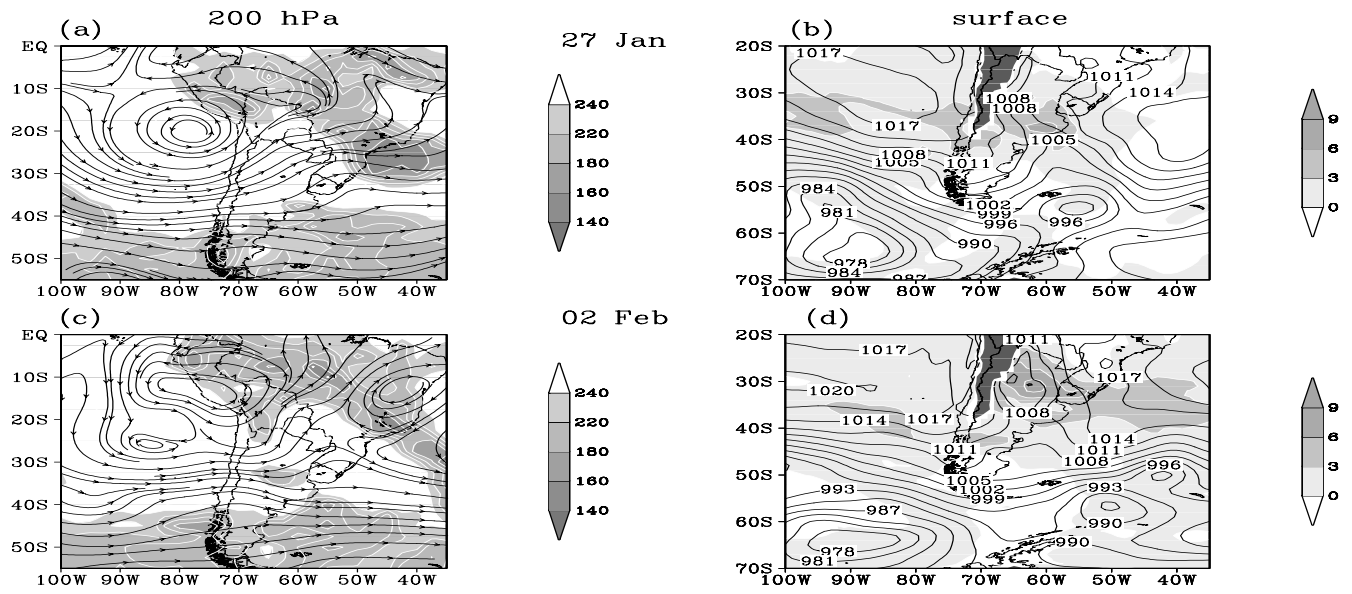

Figure 6: (Left) 200-hPa streamfunction (contour) and OLR (shaded), and (right) 950-hPa temperature anomalies (shaded) and, sea-level pressure (contour), at 12 UTC. (a, b) 27 Jan, (c, d) 2 Feb of 2003. OLR contour/shading interval is 20 watts $\mathrm{m}^{-2}$ and only values smaller than 240 watts $\mathrm{m}^{-2}$ are shaded. Contour interval is $3 \mathrm{hPa}$ for sea-level pressure. Shading interval is $3^{\circ} \mathrm{C}$ for temperature anomalies.

weakened as the extratropical trough over the southern tip of South America progressed eastward. On 31 January, the Bolivian High and the SACZ-related circulation considerably weakened as did the tropical convection (not shown). At lower levels, the extratropical front continued moving northeastward promoting the strengthening of a low-pressure center over northwestern Argentina. This cyclonic feature usually known as the "Northwestern Argentinean Low" (Seluchi et al. 2003), is a thermal-orographic system that seems to play a role in the southward intensification of the SALLJ (Saulo et al. 2004). By 2 February, the time when the temperature extreme event occurred at Rosario, the northwestern Argentinean low continued strengthening and contributing to an intensification of the warm and moist northerly flow into central and eastern Argentina (Fig 6d). The tropical circulation at upper levels is disorganized and the associated convection is rather weak (Fig. 6c). An extratropical upper-level trough remained over Patagonia contributing to intensify the low-level wind convergence over central Argentina. During the evening of 2 Feb, rainfall events occurred over eastern Argentina and temperature dropped $15.7^{\circ} \mathrm{C}$ in 6 hours that night (not shown). Figure 3 shows that both the synoptic and intraseasonal signal of the temperature decreased considerable after 2 February.

\section{Diagnosis of the thermodynamic energy equation}

In order to identify the mechanisms responsible for the occurrence of the extreme warm case, the terms of the thermodynamic energy equation were computed. This equation is expressed as:

$$
\begin{gathered}
\frac{\partial T}{\partial t}=-\mathbf{V}_{H} \cdot T-\omega \frac{\partial T}{\partial p}+\frac{1}{C_{p}} \frac{\partial Q}{\partial t} \\
A \\
B
\end{gathered}
$$

$A$ represents the temperature tendency, $B$ the horizontal temperature advection, $C$ the vertical temperature advection, and $D$ the diabatic heating term. Terms A, B, and C of Eq. (1) were evaluated using the full fields of the variables over the Rosario city location at 950, and $700 \mathrm{hPa}$ levels that represent the temperature evolution near surface and aloft respectively. Figure 2 shows that the temperature tendencies described by GDAS data are consistent with those observed in Rosario although smaller. The diabatic heating term was computed from equation (1) as the residual term. Figure 7 displays the evolution of the different terms between 27 January and 3 February 2003.

Positive temperature tendencies occurred between 27 and 30 January mostly associated with vertical temperature advection at $700 \mathrm{hPa}$ (Fig. 7a) and diabatic warming at $950 \mathrm{hPa}$ (Fig. $7 b)$. Both, the convection at the tropics and the extratropical anticyclone development (Fig. 6), favored subsidence and clear sky conditions over 
Rosario that in turn promoted adiabatic warming and sensible heat release. Between 31 January

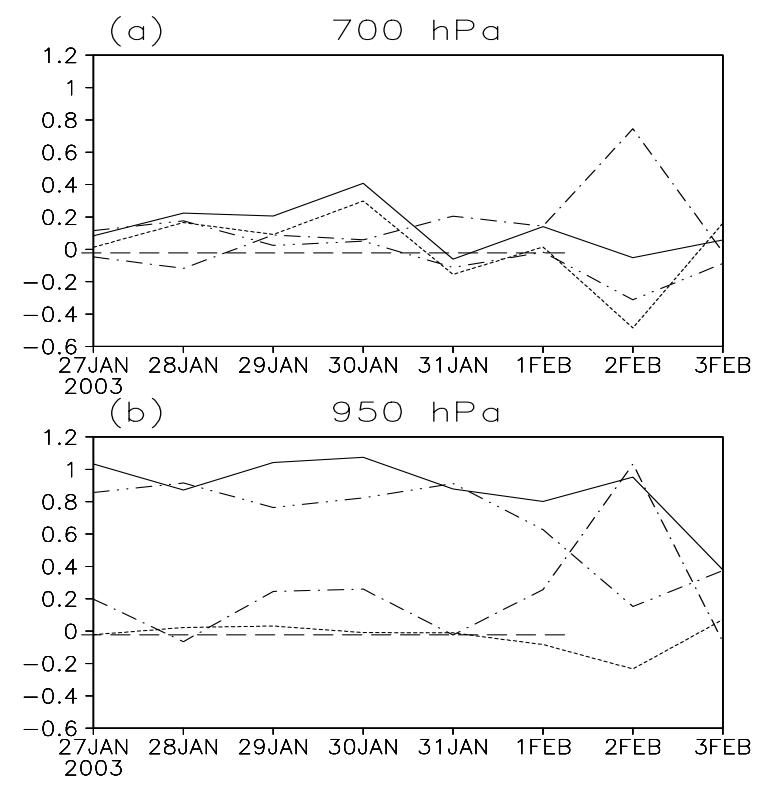

Figure 7: Terms of the thermodynamic equation computed between 27 January and 3 February 2003 at (a) $700 \mathrm{hPa}$ and, (b) $950 \mathrm{hPa}$ : temperature tendency (solid line), horizontal temperature advection (dotteddashed line), vertical temperature advection (dash) and diabatic heating term (dotted-dotted-dashed line).

and 2 February, the horizontal advection term became the most important mechanism in both levels, favored by the progression of the extratropical front from the south (Fig. 6), that also contributed to weaken the contribution of the adiabatic term. Also, the diabatic warming started to decrease (likely due to an increment of the cloudiness), and became negative at $700 \mathrm{hPa}$, while it still remained positive at $950 \mathrm{hPa}$. After 2 Feb, a cold air outbreak occurred that dropped markedly the values of both temperature tendency and temperature advection terms.

\section{Conclusions}

This paper describes the main characteristics of a heat wave that occurred over central Argentina between 25 January and 2 February of 2003 that produced the historical largest February records of temperature in the last 35 years. SALLJEX experiment was carried out in the region of study during that particular summer, which provided an unusually dense upper-level data coverage.
Temperature anomalies over central Argentina during that summer showed considerable variability on both synoptic and intraseasonal timescales. Moreover, it was found that a combined influence of the activity of synoptic waves and that of intraseasonal oscillation (which resembled the known SASS pattern) contributed to set the warm environment over subtropical South America, favorable for the SALLJEX heat wave.

During the second half of January 2003, SACZ-like enhanced convection was observed over southeastern Brazil that promoted dry and warm conditions over central Argentina, through subsidence mechanisms. The progression of an extratropical anticyclone from the South Pacific into the continent also contributed to reinforce such subsidence conditions. By the end of January, the weakening of the convection in the SACZ region and the progressive intensification of the northerly low-level flow along the eastern slopes of the Andes into the subtropics, contributed to decrease the subsidence conditions and to increase the warming processes by horizontal advections. In such environment, the progression of an extratropical frontal system into the region resulted in a temperature peak in central Argentina by 2 February.

The analysis of the terms of the thermodynamic energy equation confirmed that adiabatic subsidence and diabatic warming associated with the SACZ activity, followed by the horizontal advection associated with the southward intensification of the SALLJ were the leading mechanisms promoting the development of the SALLJEX heat wave in subtropical South America. To our knowledge there are no previous studies addressing the influence of the intraseasonal evolution associated with the SACZ onto the daily temperature variability and temperature extreme event occurrence over this particular region. Therefore, future works are planned in order to assess whether the mechanisms discussed here are a more common characteristic of the tropical-extratropical interactions over South America, which it would certainly contribute to increase the predictability levels in the region beyond the synoptic timescales.

\section{Acknowledgments}

This work was supported by NOAA/GC03-011, Inter-American Institute for Global Change (CRN055), University of Buenos Aires (X264), and CONICET/PEI-6391. We acknowledge the 
Environmental Research Service for supplying a free version of the RAOB to analyze the SALLJEX soundings. SALLJEX was funded by NOAA/OGP, NSF (ATM0106776) and funding agencies from Brazil FAPESP Grant 01/13816-1) and Argentina (ANPCYT PICT 07-06671, UBACyT 055). ANPCyT (PICTs 99-76355 and 07-09950). NCEPNCAR reanalyses and OLR dataset were made available through the Climate Diagnostic Center (http://www.cdc.noaa.gov).

\section{References}

Alessandro, A. P., and A. B. de Garín, 2003: A study on predictability of human physiological strain in Buenos Aires City. Meteorol. Appl., 10, 263-271.

Campetella, C., and M. Rusticucci, 1998: Synoptic analysis of an extreme heat wave over Argentina in March 1980. Meteorol. Appl., 5, 217-226.

Cerne, S. B., and N. E. Possia, 2004: Evolution of South American high pressure systems during late summer 1997. Meteorol. Appl., 11, 329-341.

Gandu, A.W., and P. L. Silva Dias, 1998: Impact of Tropical Heat Sources on the South American Tropospheric Upper Circulation and Subsidence. J. Geophys. Res., 103, 6001-6015.

Kalnay, E., and Coauthors, 1996: The NCEP/NCAR 40-Year Reanalysis Project. Bull. Amer. Meteor. Soc., 77, 437-471.

Lee, D., and A. Henschel, 1966: Effects of physiological and clinical factors on the response to heat. Ann NY Acad. Sci., 134, 734-749.

Liebmann, B., G. N. Kiladis, C. S. Vera, A. C. Saulo and L. M. V. Carvalho, 2004: Subseasonal Variations of Rainfall in South America in the Vicinity of the Low-Level Jet East of the Andes and Comparison to Those in the South Atlantic Convergence Zone. J. Climate, 17, 3829-3842.

Nogues-Paegle, J., and K. Mo, 1997: Alternating wet and dry conditions over South America during summer. Mon. Wea. Rev., 125, 279291.

Rusticucci M., 1995. Regional variability of 6hourly and daily surface temperatures over Argentina. Ph.D. Tesis, University of Buenos Aires, 144 pp. [Available from Departamento de Ciencias de la Atmósfera y los Océanos. Fac. de Ciencias Exactas y Naturales. Ciudad Universitaria. 1428. Ciudad de Buenos Aires. Argentina] and W. Vargas, 1995. Synoptic situations related to spells of extreme temperatures over Argentina. Meteorol. Appl., 2, 291-300. , and V. Kousky, 2002. A comparative study of maximum and minimum temperatures over Argentina: NCEP-NCAR reanalysis versus station data. J. Climate, 15, 2089-2101.

Saulo C., M. E. Seluchi and M. Nicolini, 2004. A Case Study of a Chaco Low-Level Jet Event. Mon, Wea. Rev., 132, 2669-2683.

Seluchi, M., A. C., Saulo, M. Nicolini and P. Satyamurty, 2003: The Northwestern Argentinean Low: A Study of Two Typical Events. Mon. Wea. Rev., 131, 2361-2378.

Vera, C.; J. Baez; M. Douglas; C. B. Emmanuel; J. Marengo; J. Meitin; M. Nicolini; J. No-guesPaegle; J. Paegle; O. Penalba; P. Salio; C. Saulo; M. A. Silva Dias; P. Silva Dias; and E. Zipser, 2005: The South American LowLevel Jet Experiment (SALLJEX). Bull. Amer. Meteor. Soc., (accepted). 